\title{
Distal Esophageal Impedance Measured by High-resolution Esophageal Manometry With Impedance Suggests the Presence of Barrett's Esophagus
}

\author{
Rahul Kataria, ${ }^{1}$ Benjamin Rosenfeld, ${ }^{2 *}$ Zubair Malik, ${ }^{1}$ Martha Harrison, ${ }^{1}$ Michael S Smith, ${ }^{1}$ Ron Schey, ${ }^{1}$ and Henry P Parkman ${ }^{1}$ \\ ${ }^{I}$ Division of Gastroenterology and ${ }^{2}$ Department of Internal Medicine, Temple University Hospital, Philadelphia, PA, USA
}

\begin{abstract}
Background/Aims
Barrett's esophagus (BE) is characterized by intestinal metaplasia in the distal esophagus. The aims of this study are to: (1) Compare baseline distal esophageal impedance (DEI) using high-resolution esophageal manometry with impedance (HREMI) in patients with $\mathrm{BE}$, esophagitis, and healthy volunteers and (2) Correlate length of low impedance on HREMI in patients with $\mathrm{BE}$ to the length of endoscopic BE.
\end{abstract}

\section{Methods}

Patients with BE or esophagitis who underwent HREMI were included. Ten volunteers had HREMI. Baseline DEI was calculated from HREMI using the landmark segment. In patients with $B E$, the impedance was plotted to measure the extent of plotted low impedance (PLI) and visual low impedance (VLI). Lengths of VLI and PLI were correlated to endoscopic length of BE by Prague score.

\section{Results}

Forty-five patients were included (16 BE; 19 esophagitis; 10 volunteers). BE patients had lower baseline DEl at the first, second, and third sensors above the lower esophageal sphincter (mean \pm SEM: $1.37 \pm 0.45,0.97 \pm 0.27$, and $0.81 \pm 0.20$ ) compared to volunteers $(8.73 \pm 0.60,8.20 \pm 0.73$, and $6.94 \pm 0.99 ; P<0.001)$. Baseline DEI was lower in BE than esophagitis patients $(2.98 \pm 0.65,2.49 \pm$ 0.56 , and $2.01 \pm 0.51)$ at the first, second, and third sensors $(P<0.052$ for second and third sensors); ie, BE $<$ esophagitis $<$ controls. $\mathrm{PLI}$ and VLI had a stronger correlation to circumferential score $\left(r^{2}=0.84\right.$ and 0.83$)$ than maximal score $\left(r^{2}=0.76\right.$ and 0.68$)$.

\section{Conclusions}

Baseline DEI is lower in BE compared with esophagitis and healthy volunteers. The length of low impedance correlates to the endoscopic extent of BE. Thus, impedance values during HREMI may help suggest the presence and extent of BE or esophagitis.

(J Neurogastroenterol Motil 2020;26:344-351)

\section{Key Words}

Barrett esophagus; Electric impedance; Esophagitis; Gastroesophageal reflux

\section{Received: May 13, 2019 Revised: July 3, 2019 Accepted: December 18, 2019}

() This is an Open Access article distributed under the terms of the Creative Commons Attribution Non-Commercial License (http://creativecommons. org/licenses/by-nc/4.0) which permits unrestricted non-commercial use, distribution, and reproduction in any medium, provided the original work is properly cited.

*Correspondence: Benjamin Rosenfeld, MD

Department of Internal Medicine, Temple University Hospital, Parkinson Pavilion, 8th Floor, 3401 N Broad Street, Philadelphia, PA 19140, USA

Tel: +1-267-530-1403, Fax: +1-646-658-4205, E-mail: benjamin.rosenfeld@tuhs.temple.edu 


\section{Introduction}

Evaluation of gastroesophageal reflux disease (GERD) traditionally has been performed with esophageal $\mathrm{pH}$ monitoring which detects acid reflux. ${ }^{1}$ Multichannel intraluminal impedance-pH (MII-pH) testing allows for measurement of any form of reflux by detecting retrograde fluid flow in the esophagus (irrespective of $\mathrm{pH}$ ). The impedance technology detects a change in electrical resistance between 2 electrodes: a liquid bolus leads to a lower impedance measurement compared to a gas bolus. Barrett's esophagus (BE) is believed to result from chronic exposure to refluxate from GERD. It is characterized by specialized (goblet cell) intestinal metaplasia in the distal esophagus. Similarly, in esophagitis, a disruption of healthy mucosa occurs. The altered mucosal integrity results in dilation of the intercellular space, allowing increased flow of electrolyte-rich fluid around the cells. ${ }^{2-4}$ As a result, the mucosa is able to better conduct electrical current, leading to lower impedance compared to the normal mucosa.

Using these principles, Kessing et al $l^{5}$ in 2011 used MII-pH to investigate the baseline esophageal impedance in GERD patients and healthy controls. The catheter used for MII-pH studies allows for impedance measurement at $3 \mathrm{~cm}$ and $17 \mathrm{~cm}$ above the lower esophageal sphincter (LES); the study showed that the average baseline impedance ( $3 \mathrm{~cm}$ above the LES) was significantly lower in patients with pathological acid exposure than controls. ${ }^{5}$ This was also shown in 2011 by Farre et al, ${ }^{6}$ who measured baseline impedance using a MII-pH catheter at 3, 5, and $7 \mathrm{~cm}$ above the LES before, during, and after perfusion with a neutral solution ( $\mathrm{pH} 7.2)$ and 2 acidic solutions ( $\mathrm{pH} 2.0$ and $\mathrm{pH} 1.0$ ) in 8 healthy volunteers. They found that the baseline impedance in patients with esophagitis was significantly lower than in healthy volunteers. ${ }^{6}$

Similar to MII-pH, high-resolution esophageal manometry with impedance (HREMI) uses a catheter with impedance sensors; however, it provides more impedance data over the length of the esophagus with 18 impedance sensors (every $2 \mathrm{~cm}$ ). Therefore, HREMI should also be able to expand upon and refine prior study results. Recently, HREMI has been used to accurately discriminate GERD patients from healthy controls using baseline impedance measurements ${ }^{7}$; however, HREMI for this purpose has limited data.

Thus far, it has been reported that mucosal changes in BE result in a lower impedance level than those with esophagitis. ${ }^{8}$ Sifrim et $\mathrm{al}^{9}$ in 2000 showed that patients with $\mathrm{BE}$ have a lower mucosal impedance than both those with esophagitis and healthy volunteers.
One proposed theory to explain this finding is that reflux exposure results in microscopic esophageal mucosal changes such as dilated intracellular spaces and disruption of tight junctions. ${ }^{2,10}$ Columnar cells have been shown to have lower impedance measurements than squamous cells due to the above-mentioned changes. ${ }^{11}$ Using the visual impedance setting during the HREMI, we noticed a length of low impedance (characterized by purple color used for low impedance values) in patients with $\mathrm{BE}$.

The aim of our study is to compare baseline esophageal impedance using HREMI in patients with BE, esophagitis, and healthy volunteers. An additional aim is to measure the length of low baseline esophageal impedance in patients with BE using HREMI and correlate to the length of endoscopically and biopsy measured BE.

\section{Materials and Methods}

\section{Patients}

After obtaining Institutional Review Board approval (IRB No. 4855), a retrospective review of our endoscopy, pathology, and esophageal manometry records from January 2013 to December 2016 was performed. Any patient with an upper endoscopy and biopsy proven BE or esophagitis, as well as HREMI within 120 days of their endoscopy was included. Patients with achalasia, or previously endoscopically or surgically treated $\mathrm{BE}$ were excluded. Additionally, 10 healthy volunteers without symptoms and no previous proton pump inhibitor (PPI) treatment had HREMI performed. Clinical notes were reviewed to determine demographics, endoscopy findings, and biopsy results. Among patients with esophagitis, the severity of the esophagitis using the Los Angeles classification was observed. ${ }^{12}$ For patients with known BE, the endoscopy report was evaluated for endoscopic measurement of $\mathrm{BE}$ for which the Prague classification was used ${ }^{13}$ measuring the circumferential (C) and maximal $(\mathrm{M})$ extent. Biopsy results were used as an additional measurement of length, using the Seattle protocol with 4-quadrant biopsies being taken at least every $2 \mathrm{~cm}$ along the length of visualized BE. ${ }^{14}$

\section{High-resolution Esophageal Manometry With Impedance}

HREMI studies were performed using a solid-state catheter consisting of 36 circumferential pressure sensors spaced $1 \mathrm{~cm}$ apart and 18 impedance sensors spaced $2 \mathrm{~cm}$ apart (Medtronic Inc, Shoreview, MN, USA). The catheter was inserted trans-nasally with the patient in a seated position. The patient was then placed 
supine followed by 5 minutes to equilibrate the catheter to body temperature. A landmark calibration phase was recorded for 30 seconds prior to administering any wet swallows. During this time period, impedance measurements were recorded. This was then followed by twelve $5 \mathrm{~mL}$ saline swallows spaced 20-30 seconds apart. All tracings were reviewed using Manoview Analysis Software version 3.0.1 (Medtronic Inc, Minneapolis, Minnesota) and classified per the Chicago classification version 3.0. ${ }^{15}$

\section{Baseline Distal Esophageal Impedance Measurement}

Baseline DEI was calculated from each HREMI study for the first 3 impedance sensors above the LES using the average impedance during the 30-second landmark period prior to 12 wet swallows. In order to determine which 3 impedance sensors were located closest to the proximal border of the LES, the pressure sensor closest to the LES was marked. From this marked pressure sensor, the first 3 impedance sensors above the LES were identified. The values from all impedance sensors during this landmark period were exported from Manoview to Excel (Microsoft, Redmond, WA, USA) for analysis. Average impedance values at each sensor over the 30-second landmark period were calculated for each patient.

\section{Low Impedance High-resolution Esophageal Manometry With Impedance Analysis}

In patients with $\mathrm{BE}$, visual analysis of the low impedance on HREMI (visual low impedance [VLI]) was assessed during the landmark period. The length of low impedance was obtained using the color contour plot view by measuring the extent of purple shade (indicating low impedance) from the LES. For calibration of the color impedance, the saturation of the purple shade was increased until a noticeable cut point was seen. The marker for the upper border of the LES was used to measure the proximal extent of the purple shade from the LES while the distal extent was measured with the LES marker (Fig. 1). The average impedance values at each impedance sensor, calculated from the exported data in Microsoft Excel during the landmark period, were then plotted and an inflection point on the graph was identified. The pressure sensor closest to the LES was also recorded. The extent of plotted low impedance (PLI) was reported as the distance from the pressure sensor closest to the LES, to the impedance sensor at which the inflection point was noted (Fig. 1).

\section{Statistical Methods}

Statistical analysis was performed using Microsoft Excel and SAS 9.2 (Cary, NC, USA). Data were reported as means and population percentages with SEM. Comparisons of the differences between the least square means of baseline DEI between patient groups were made using the MIXED procedure in SAS. Lengths of VLI and PLI were correlated to the endoscopic length of BE by the Prague score, $\mathrm{C}$ and $\mathrm{M}$ extent, as well as pathologic length of BE by biopsy specimens taken at every centimeter along the visualized BE. The endoscopic Prague scores were measured by a single endoscopist (M.S.S.). The correlation of VLI and PLI to length

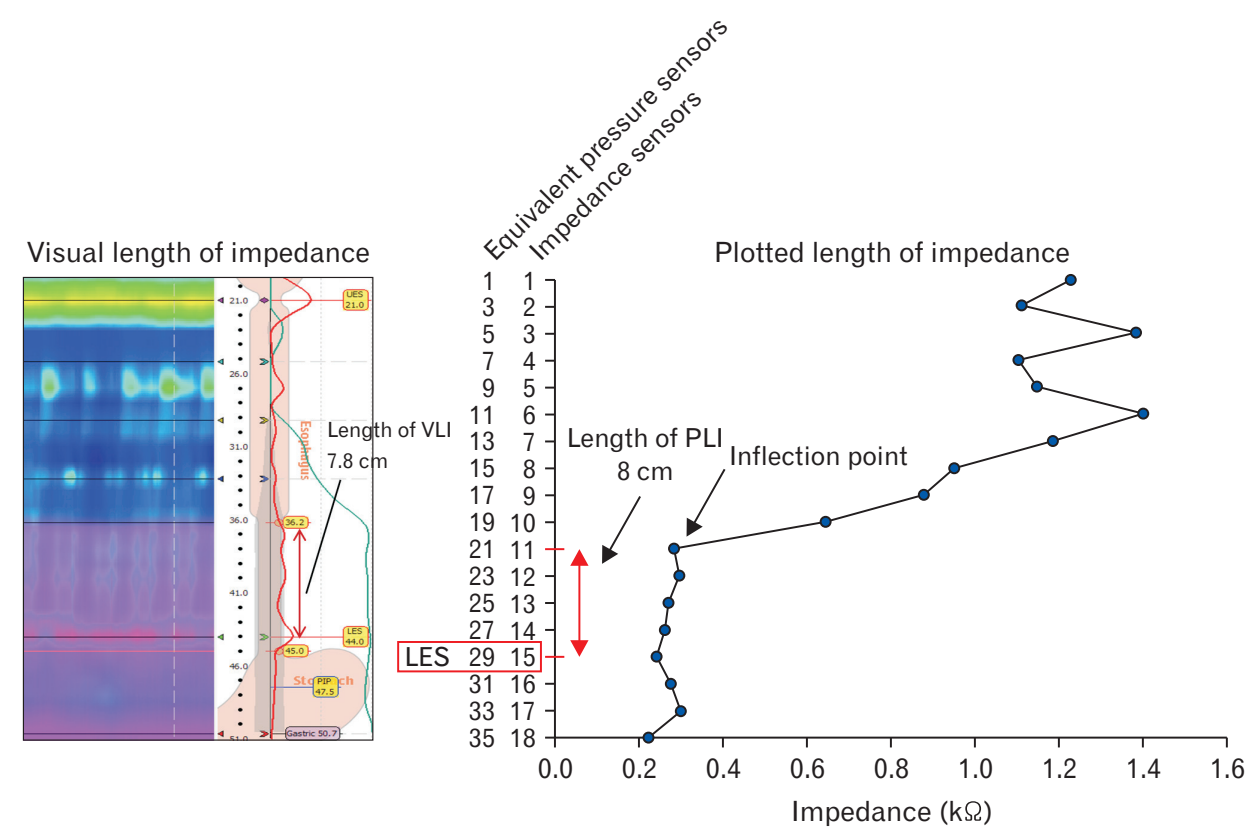

Figure 1. Analysis of low impedance by high-resolution esophageal manometry with impedance in patient with Barrett's esophagus (BE). On the left is an example of how visual length of low impedance is measured. On the right is an example of the same patient who had the plotted length of low impedance measured. VLI, visual low impedance; PLI, plotted low impedance; LES, lower esophageal sphincter. 
of $\mathrm{BE}$ was assessed using the Pearson's correlation coefficient. $P$ values of less than 0.05 were considered statistically significant.

\section{Results}

\section{Demographics}

Forty-five patients (26 males; mean age 52 [24-82] years) were included in the study (Tables 1 and 2). Sixteen patients (10 male, mean age 63 [40-82] years) had biopsy proven BE without esophagitis (mean Prague score C4M7). Of the patients with BE, 9/16 had preserved peristalsis (mean distal contractile integral $1874.5 \pm$ $108.0 \mathrm{mmHg} \cdot \mathrm{cm} \cdot \mathrm{sec}$ ) while the remaining $7 / 16$ had ineffective motility (mean distal contractile integral $337.9 \pm 65.0 \mathrm{mmHg} \cdot \mathrm{cm} \cdot \mathrm{sec}$ ). Low grade dysplasia was seen in only one patient $(6.25 \%)$, while the rest had no dysplasia by biopsy. Fifteen of 16 patients had a hiatal hernia seen on HREMI (length of hiatal hernia $3.1 \pm 0.2 \mathrm{~cm}$ ). All 16 patients were on high dose PPI therapy. Nineteen patients (8 male, mean age 54 [28-75] years) had biopsy proven esophagitis without BE. Of the 19 patients with esophagitis, using the Los Angeles classification, 10 patients had grade A, 3 patients had grade B, 5 patients had grade $\mathrm{C}$, and 1 patient had grade $\mathrm{D}$. Twelve of the 19 patients had a hiatal hernia seen on HREMI (length of hiatal hernia $2.3 \pm 0.3 \mathrm{~cm}$ ). Ten healthy volunteers ( 8 male, mean age 31 [24-35] years) also were studied.

\section{Baseline Distal Esophageal Impedance}

Mean baseline $\mathrm{DEI}$ in $\mathrm{k} \Omega$ at the first, second, and third sensors from the LES was significantly lower in patients with $\mathrm{BE}$ (mean \pm SEM: $1.37 \pm 0.45,0.97 \pm 0.27$, and $0.81 \pm 0.20$ ) compared to the healthy volunteers $(8.73 \pm 0.60,8.20 \pm 0.73$, and $6.94 \pm 0.99$; $P<0.001$ ) (Fig. 2). Similarly, the mean baseline DEI at the first, second, and third sensors above the LES was significantly lower in patients with esophagitis $(2.98 \pm 0.65,2.49 \pm 0.56$, and $2.01 \pm$ $0.51)$ compared to healthy volunteers $(P<0.001)$. The baseline $\mathrm{DEI}$ in patients with $\mathrm{BE}$ was lower at the first, second, and third sensors above the LES when compared to patients with esophagitis, however statistical significance was seen only at the second and third sensors $(P<0.052)$.

\section{Length of Low Impedance Compared to Length of Barrett's Esophagus}

The Prague $\mathrm{C}$ score ranged from $0 \mathrm{~cm}$ to $10 \mathrm{~cm}$ (mean \pm SEM; $4.3 \pm 0.9 \mathrm{~cm}$ ), and the M score ranged from $2 \mathrm{~cm}$ to 12 $\mathrm{cm}(6.7 \pm 0.8 \mathrm{~cm})$. Correlation between PLI and the endoscopic Prague $\mathrm{M}$ score in patients with $\mathrm{BE}$ was statistically significant with a strong linear fit $\left(r^{2}=0.76, P<0.015\right)$. Correlation between PLI and the endoscopic Prague $\mathrm{C}$ score in patients with $\mathrm{BE}$ was statistically significant and had a stronger correlation $\left(r^{2}=0.84, P<\right.$ $0.015)$. VLI also had a stronger correlation to the $\mathrm{C}$ score $\left(r^{2}=0.83\right.$,

Table 1. Characteristics of Patients With Barrett's Esophagus

\begin{tabular}{|c|c|c|c|c|c|c|c|c|c|}
\hline Patient & $\begin{array}{l}\text { Age } \\
(\mathrm{yr})\end{array}$ & Sex & $\begin{array}{c}\text { BMI } \\
\left(\mathrm{kg} / \mathrm{m}^{2}\right)\end{array}$ & PPI use ${ }^{a}$ & $\begin{array}{c}\text { Indication } \\
\text { for HREMI }\end{array}$ & $\begin{array}{c}\text { Chicago } \\
\text { classification }\end{array}$ & $\begin{array}{c}\text { Hiatal } \\
\text { hernia size }(\mathrm{cm})\end{array}$ & Prague score & $\begin{array}{l}\text { Dysplasia } \\
\text { by biopsy }\end{array}$ \\
\hline 1 & 82 & $\mathrm{~F}$ & 22.4 & $\mathrm{Y}$ & ARS & Normal & 3.8 & C10M12 & $\mathrm{N}$ \\
\hline 2 & 72 & $\mathrm{~F}$ & 30.5 & $\mathrm{Y}$ & ARS & IEM & 0.0 & C10M10 & $\mathrm{N}$ \\
\hline 3 & 48 & M & 34.9 & $\mathrm{Y}$ & ARS & IEM & 3.5 & $\mathrm{C} 8 \mathrm{M} 12$ & $\mathrm{~N}$ \\
\hline 4 & 65 & M & 28.7 & $\mathrm{Y}$ & ARS & Normal & 2.5 & C7M9 & $\mathrm{N}$ \\
\hline 5 & 68 & M & 38.0 & $\mathrm{Y}$ & ARS & Normal & 1.3 & C7M9 & $\mathrm{N}$ \\
\hline 6 & 55 & $\mathrm{~F}$ & 34.3 & $\mathrm{Y}$ & ARS & Normal & 3.2 & $\mathrm{C} 7 \mathrm{M} 8$ & $\mathrm{~N}$ \\
\hline 7 & 60 & $\mathrm{~F}$ & 22.9 & $\mathrm{Y}$ & ARS & IEM & 4.2 & $\mathrm{C} 5 \mathrm{M} 8$ & LGD \\
\hline 8 & 74 & M & 28.9 & $\mathrm{Y}$ & ARS & IEM & 3.2 & $\mathrm{C} 5 \mathrm{M} 6$ & $\mathrm{~N}$ \\
\hline 9 & 71 & M & 27.1 & $\mathrm{Y}$ & ARS & IEM & 3.0 & $\mathrm{C} 4 \mathrm{M} 8$ & $\mathrm{~N}$ \\
\hline 10 & 74 & M & 26.3 & $\mathrm{Y}$ & ARS & IEM & 4.8 & $\mathrm{C} 2 \mathrm{M} 5$ & $\mathrm{~N}$ \\
\hline 11 & 40 & M & 34.0 & $\mathrm{Y}$ & ARS & Normal & 3.7 & $\mathrm{C} 2 \mathrm{M} 5$ & $\mathrm{~N}$ \\
\hline 12 & 57 & M & 24.6 & $\mathrm{Y}$ & ARS & IEM & 2.2 & $\mathrm{C} 1 \mathrm{M} 3$ & $\mathrm{~N}$ \\
\hline 13 & 61 & $\mathrm{~F}$ & 21.6 & $\mathrm{Y}$ & ARS & Normal & 3.8 & $\mathrm{C} 0 \mathrm{M} 3$ & $\mathrm{~N}$ \\
\hline 14 & 72 & $\mathrm{~F}$ & 23.2 & $\mathrm{Y}$ & ARS & Normal & 2.9 & $\mathrm{C} 0 \mathrm{M} 2$ & $\mathrm{~N}$ \\
\hline 15 & 50 & M & 26.0 & $\mathrm{Y}$ & ARS & Normal & 2.2 & $\mathrm{C} 0 \mathrm{M} 3$ & $\mathrm{~N}$ \\
\hline 16 & 52 & M & 25.5 & $\mathrm{Y}$ & ARS & Normal & 2.2 & $\mathrm{C} 0 \mathrm{M} 4$ & $\mathrm{~N}$ \\
\hline
\end{tabular}

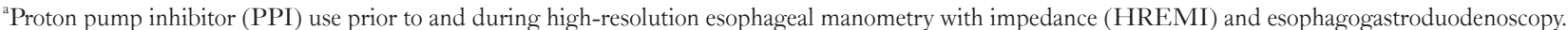
BMI, body mass index; F, female; M, male; Y, yes; ARS, anti-reflux surgery; IEM, ineffective esophageal motility; N, no; LGD, low grade dysplasia. 
Table 2. Characteristics of Patients With Esophagitis

\begin{tabular}{ccccclcc}
\hline Patient & $\begin{array}{c}\text { Age } \\
(\mathrm{yr})\end{array}$ & Sex & $\begin{array}{c}\text { BMI } \\
\left(\mathrm{kg} / \mathrm{m}^{2}\right)\end{array}$ & PPI use & $\begin{array}{c}\text { Indication } \\
\text { for HREMI }\end{array}$ & Chicago & \multicolumn{2}{c}{$\begin{array}{c}\text { Hiatal } \\
\text { classification }\end{array}$} & $\begin{array}{c}\text { LA esophagitis } \\
\text { hernia size }(\mathrm{cm})\end{array}$ \\
grade
\end{tabular}

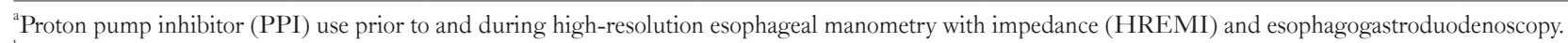

${ }^{\mathrm{b}}$ Los Angeles (LA) esophagitis definitions: Grade A, one or more mucosal breaks $<5 \mathrm{~mm}$ in maximal length; Grade B, one or more mucosal breaks $>5 \mathrm{~mm}$, but without continuity across mucosal folds; Grade $\mathrm{C}$, mucosal breaks continuous between $\geq 2$ mucosal folds, but involving less than $75 \%$ of the esophageal circumference; and Grade D, mucosal breaks involving more than $75 \%$ of esophageal circumference.

BMI, body mass index; F, female; M, male; N, no; Y, yes; ARS, anti-reflux surgery; IEM, ineffective esophageal motility.

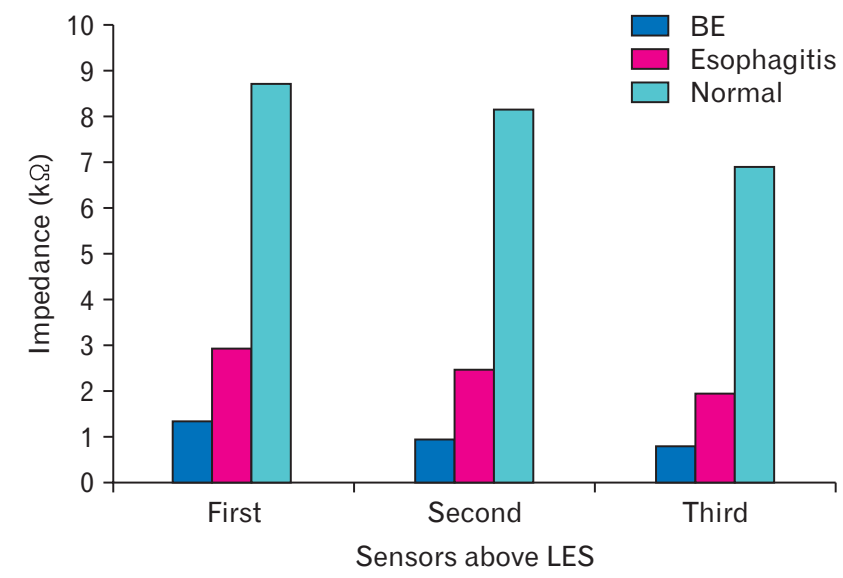

Figure 2. Baseline distal esophageal impedance $(\mathrm{k} \Omega)$ values at the first, second, and third sensor above the lower esophageal sphincter (LES). BE, Barrett's esophagus.

$P<0.015)$ than $\mathrm{M}$ score $\left(r^{2}=0.68, P<0.015\right)$, both statistically significant. Comparison of PLI to the length of BE by biopsy had a good correlation $\left(r^{2}=0.67, P<0.015\right)$, as did VLI to the length of BE by biopsy $\left(r^{2}=0.64, P<0.015\right)$ (Fig. 3).

\section{Discussion}

Our study shows a novel application of the impedance measurements during HREMI studies: abnormally low impedance in the distal esophagus is associated with esophagitis and BE. Related to our first aim, we found the baseline DEI to be significantly lower in patients with both $\mathrm{BE}$ and esophagitis when compared to healthy controls. Similarly, the baseline DEI was lower in patients with BE when compared to those with esophagitis. Our second aim was to measure the length of low impedance in patients with $\mathrm{BE}$ seen on HREMI and compare this to the length of endoscopically and biopsy measured $\mathrm{BE}$. We found a strong correlation between the length of low impedance and the length of BE by Prague score.

The use of intraluminal esophageal impedance measurement during MII-pH studies for assessment of reflux has been widely described and validated, with reflux defined as a retrograde $50 \%$ decrease in impedance. ${ }^{16,17}$ There is limited research on its use to assess mucosal integrity. An initial study was performed using a single-channel mucosal impedance catheter during esophagogastro- 

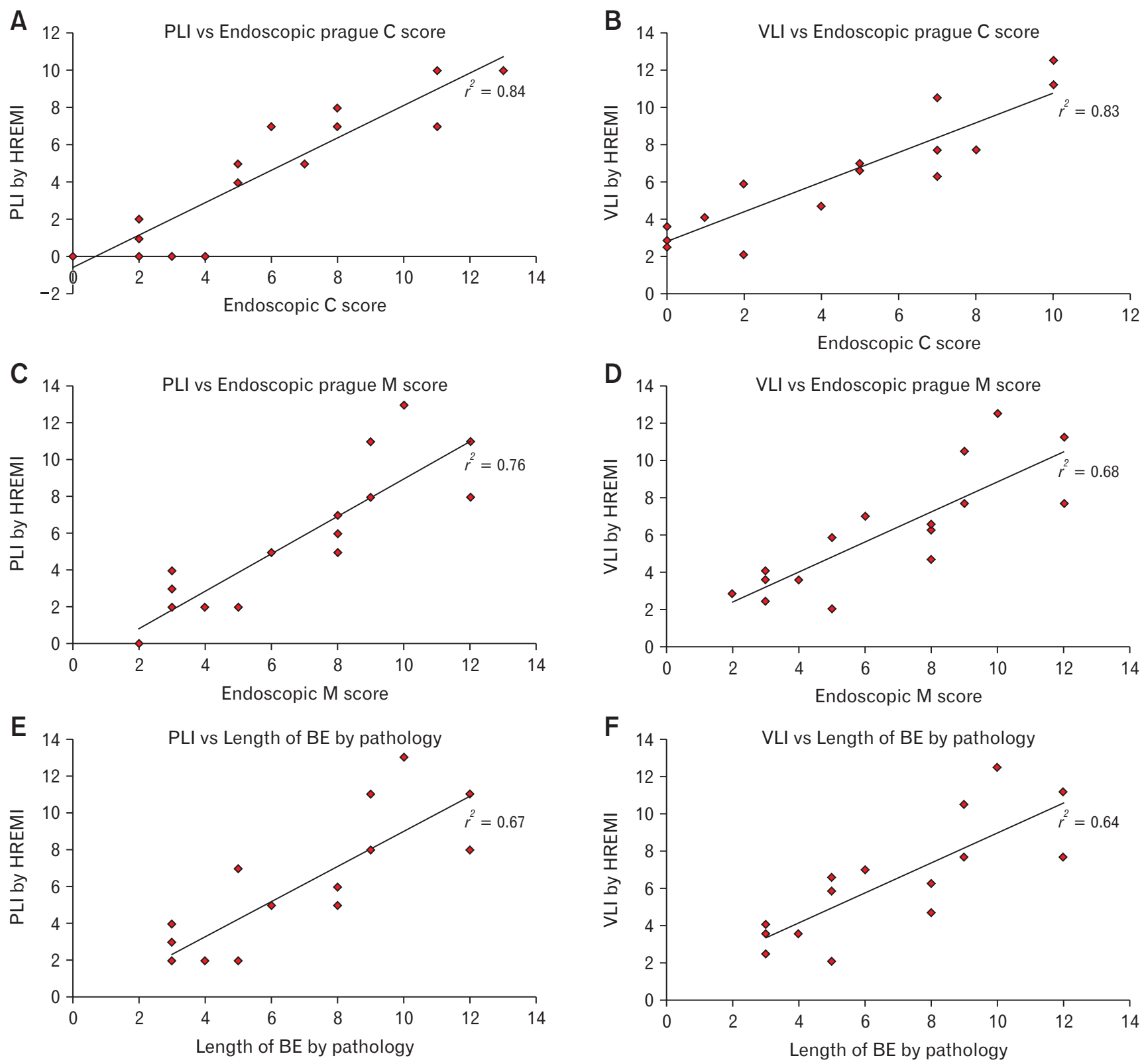

Figure 3. Comparison of Barrett's Esophagus (BE) length measurements taken via high-resolution esophageal manometry with impedance (HREMI) versus length established by Prague scores (circumferential [c] or maximal [M]) or pathology. (A) HREMI length of plotted low impedance (PLI) versus endoscopic C score. (B) HREMI length of visualized low impedance (VLI) versus endoscopic C score. (C) HREMI length of PLI versus endoscopic M score. (D) HREMI length of VLI versus endoscopic M score. (E) HREMI length of PLI versus length of $\mathrm{BE}$ confirmed on pathology. (F) HREMI length of VLI versus length of BE confirmed on pathology.

duodenoscopy to measure direct mucosal impedance in 19 patients with erosive esophagitis, 23 with non-erosive but pH-positive GERD, and 27 without GERD. Significantly lower impedance was found at the distal esophagus in patients with GERD compared to those without reflux. ${ }^{18}$ More recently, Ravi et $\mathrm{al}^{7}$ showed that HREMI and MII-pH baseline impedance measurements correlate well with one another. Furthermore, baseline impedance during HREMI appeared to differentiate GERD patients from healthy controls using impedance values: reflux patients had significantly lower impedance than normal controls. ${ }^{7}$ This supports our use of HREMI to assess for alterations of impedance in patients with esophagitis or BE. 
We found that baseline DEI was significantly lower in patients with $\mathrm{BE}$ or reflux esophagitis compared to healthy volunteers. The reason for this change in impedance is thought to be due to mucosal structural changes, resulting in a columnar cell mucosa with increased epithelial permeability. This leads to an increased amount of ion-filled fluid in the intercellular spaces, and subsequently a decreased impedance measurement. ${ }^{10,11}$ Previous studies suggest approximately a $2.1 \mathrm{k} \Omega$ cutoff baseline impedance value between patients with GERD and functional heartburn or healthy volunteers. Among GERD patients, those with erosive esophagitis had an even lower baseline impedance value $(\leq 1.0 \mathrm{k} \Omega){ }^{19,20}$ In our cohort of patients with esophagitis, the baseline impedance was higher (2.01-2.98 $\mathrm{k} \Omega$ ) than previously reported. This discrepancy may be because the majority of those patients underwent testing having been on high dose PPI therapy.

We also found a strong correlation between the length of low impedance and the length of $\mathrm{BE}$ by $\mathrm{C}$ score, $\mathrm{M}$ score, and pathology. The strongest correlation, however, was to the $\mathrm{C}$ score, followed by the M score. The length of BE by pathology had the weaker correlation of the three. One explanation for this is that random 4-quadrant biopsies often miss the diagnosis of $\mathrm{BE}$ because it can be focally distributed within the columnar-lined mucosa. ${ }^{21}$ The strong correlation of the length of low impedance by HREMI to the length of $\mathrm{BE}$ suggests a potential use of HREMI to help assess the length of $\mathrm{BE}$.

Our pilot observational retrospective study has several limitations that can be improved upon in subsequent prospective studies. In this pilot study, our cohort of patients was small, consisting of 16 patients with $\mathrm{BE}, 19$ patients with esophagitis, and 10 healthy volunteers. The group of healthy volunteers was male dominant and had a lower age range than the other groups. Additionally, a selection bias exists in our patients with $\mathrm{BE}$ and esophagitis because the majority of these patients in this retrospective study underwent HREMI for consideration of anti-reflux surgery. The 30-second landmark period during the baseline impedance measurements was done prior to any wet swallows. Reflux of liquid gastric contents may falsely decrease the impedance; however, this is unlikely given that the impedance value would fall much lower if liquid reflux was present. ${ }^{16}$ Pooling of liquid in the distal esophagus secondary to ineffective motility or absent peristalsis with incomplete bolus clearance may cause a false decrease in impedance. However, the majority of the patients with BE had normal motility of their esophagus by manometry. There are also limitations to the accuracy at which the length of low impedance was measured using HREMI. The pressure sensors are $1 \mathrm{~cm}$ apart, which leaves a $1 \mathrm{~cm}$ margin of er- ror when locating the LES using the pressure sensor. The impedance sensors along the catheter are spaced $2 \mathrm{~cm}$ apart, which leaves a $2 \mathrm{~cm}$ margin of error when measuring the length of low impedance. The pressure and impedance values between each sensor were interpolated by the analysis software. The accuracy of this has not been assessed to our knowledge.

The findings we have described can be applied clinically to more accurately assess GERD and its complications. The measurement of impedance above the LES using HREMI could act as a supplemental tool for reflux detection in groups such as pre-lung transplant patients, where added sensitivity is desired. It provides information about the presence of mucosal changes caused by reflux. This will allow for a better assessment of reflux changes that may be missed by current methods relying on solely MII-pH studies, especially for patients where endoscopic evaluation may be limited due to comorbid conditions.

In conclusion, our study illustrates 2 novel analyses of HREMI studies. First, the distal esophageal impedance can suggest a difference between normal mucosa, esophagitis, and BE. Second, we found that using HREMI to measure the length of low impedance in patients with $\mathrm{BE}$ has a strong correlation to the endoscopic length of BE. This type of assessment can be applied clinically to patients having a HREMI for symptoms of reflux and can suggest the presence of $\mathrm{BE}$.

\section{Financial support: None.}

\section{Conflicts of interest: None.}

Author contributions: Rahul Kataria: data collection, data analysis, and study conceptualization; Benjamin Rosenfeld: data collection, study conceptualization, and manuscript review; Zubair Malik, Ron Schey, and Henry P Parkman: study conceptualization, data analysis, and manuscript review; Martha Harrison: study conceptualization, performance of high-resolution esophageal manometry with impedance; and Michael S Smith: patient enrollment and manuscript review.

\section{References}

1. Richter JE, Bradley LA, DeMeester TR, Wu WC. Normal 24-hr ambulatory esophageal $\mathrm{pH}$ values. Influence of study center, $\mathrm{pH}$ electrode, age, and gender. Dig Dis Sci 1992;37:849-856.

2. Tobey NA, Argote CM, Vanegas XC, Barlow W, Orlando RC. Electrical parameters and ion species for active transport in human esophageal stratified squamous epithelium and barrett's specialized columnar epithelium. Am J Physiol Gastrointest Liver Physiol 2007;293:G264-G270. 
3. Caviglia R, Ribolsi M, Gentile M, et al. Dilated intercellular spaces and acid reflux at the distal and proximal oesophagus in patients with nonerosive gastro-oesophageal reflux disease. Aliment Pharmacol Ther 2007;25:629-636.

4. Orlando LA, Orlando RC. Dilated intercellular spaces as a marker of GERD. Curr Gastroenterol Rep 2009;11:190-194.

5. Kessing BF, Bredenoord AJ, Weijenborg PW, Hemmink GJ, Loots $\mathrm{CM}$, Smout AJ. Esophageal acid exposure decreases intraluminal baseline impedance levels. Am J Gastroenterol 2011;106:2093-2097.

6. Farré R, Blondeau K, Clement D, et al. Evaluation of oesophageal mucosa integrity by the intraluminal impedance technique. Gut 2011;60:885892.

7. Ravi K, Geno DM, Vela MF, Crowell MD, Katzka DA. Baseline impedance measured during high-resolution esophageal impedance manometry reliably discriminates GERD patients. Neurogastroenterol Motil Published Online First: 24 Oct 2016. doi: 10.1111/nmo.12974.

8. Hemmink GJ, Alvarez Herrero L, Bogte A, et al. Esophageal motility and impedance characteristics in patients with barrett's esophagus before and after radiofrequency ablation. Eur J Gastroenterol Hepatol 2013;25:1024-1032.

9. Sifrim D, Holloway RH, Tack JF, Silny J, Lerut A, Janssens JJ. Impedance patterns at the gastroesophageal junction and distal esophagus in patients with barrett's esophagus. Gastroenterology 2000;118:A488-A489.

10. Zhong C, Duan L, Wang K, et al. Esophageal intraluminal baseline impedance is associated with severity of acid reflux and epithelial structural abnormalities in patients with gastroesophageal reflux disease. J Gastroenterol 2013;48:601-610.

11. González-Correa C, Brown BH, Smallwood RH, et al. Virtual biopsies in barrett's esophagus using an impedance probe. Ann N Y Acad Sci 1999;873:313-321.

12. Armstrong D, Bennett JR, Blum AL, et al. The endoscopic assessment of esophagitis: a progress report on observer agreement. Gastroenterology
1996;111:85-92.

13. Anand O, Wani S, Sharma P. When and how to grade barrett's columnar metaplasia: the prague system. Best Pract Res Clin Gastroenterol 2008;22:661-669.

14. Reid BJ, Blount PL, Feng Z, Levine DS. Optimizing endoscopic biopsy detection of early cancers in barrett's high-grade dysplasia. Am J Gastroenterol 2000;95:3089-3096.

15. Kahrilas PJ, Bredenoord A, Fox M, et al. The Chicago classification of esophageal motility disorders, v3. 0. Neurogastroenterol Motil 2015;27:160-174.

16. Shay SS, Bomeli S, Richter J. Multichannel intraluminal impedance accurately detects fasting, recumbent reflux events and their clearing. Am J Physiol Gastrointest Liver Physiol 2002;283:G376-G383.

17. Bredenoord AJ, Weusten BL, Timmer R, Smout AJ. Reproducibility of multichannel intraluminal electrical impedance monitoring of gastroesophageal reflux. Am J Gastroenterol 2005;100:265-269.

18. Saritas Yuksel E, Higginbotham T, Slaughter JC, et al. Use of direct, endoscopic-guided measurements of mucosal impedance in diagnosis of gastroesophageal reflux disease. Clin Gastroenterol Hepatol 2012;10:1110-1116

19. Kandulski A, Weigt J, Caro C, Jechorek D, Wex T, Malfertheiner P. Esophageal intraluminal baseline impedance differentiates gastroesophageal reflux disease from functional heartburn. Clin Gastroenterol Hepatol 2015;13:1075-1081.

20. Savarino E, de Bortoli N, Zentilin P, et al. 12 esophageal baseline impedance values correlate with presence and severity of microscopic esophagitis in patients with gastro-esophageal reflux disease. Gastroenterology 2014;146(suppl 1):S-4.

21. Sharma P. Review article: emerging techniques for screening and surveillance in barrett's oesophagus. Aliment Pharmacol Ther 2004;20(suppl 5):63-70; discusstion 95-96. 